\title{
Inibidores da enzima conversora de angiotensina são fatores de risco ou proteção na COVID-19?
}

\author{
Letícia Vieira de Souza ${ }^{a}$, Giulia Bizi Oliveiraa, Paulo Cesar Mouchalouat Filho ${ }^{a}$, Lorena Monteiro Borges ${ }^{a}$, \\ Marcella Rezende Mattos Coutinho ${ }^{\mathrm{a}}$, Marcel Vasconcellos ${ }^{\mathrm{a}}$ \\ aFaculdade de Medicina do Centro Universitário Serra dos Órgãos (UNIFESO), Teresópolis, RJ, Brasil.
}

RESUMO A partir da identificação da enzima conversora de angiotensina II (ECA2), como um receptor funcional para SARS-CoV-2, aventou-se que o uso crônico de inibidores de ECA2 e de bloqueadores do receptor $A T_{1}$ da angiotensina (BRAs II), poderia estar relacionado a regulação positiva da enzima em vários tecidos e, portanto, a uma maior suscetibilidade ao vírus. A hipótese, provocou opiniões divergentes, posto que, evidências contrárias mostraram que uma baixa expressão da ECA2 se encontra envolvida no processo patológico de lesão pulmonar após a infecção viral. Objetivamos revisar a literatura acerca do risco ou benefício do uso crônico de fármacos anti-hipertensivos em pacientes expostos ao vírus SARS-CoV-2. Realizou-se uma busca na base de dados indexados do MEDLINE/PubMed ${ }^{\circ}$, utilizando os seguintes descritores na língua inglesa: "Angiotensin-converting enzyme inhibitors"; "Angiotensin II receptor blockers"; "Hypertension"; "SARS-CoV-2"; "COVID-19". A busca resultou em 230 publicações. Após a leitura dos resumos e artigos completos disponíveis, foram selecionados 14 estudos que mostraram compatibilidade de conteúdo com o tema. Embora seja observada a falta de consenso entre pesquisadores, o uso destes fármacos não deve ser interrompido até que maiores evidências sejam obtidas acerca do uso dos fármacos anti-hipertensivos em pacientes expostos ao vírus SARS-CoV-2.

PALAVRAS-CHAVE bloqueadores do receptor de angiotensina II; hipertensão; inibidores da enzima conversora de angiotensina; SARS-CoV-2 Aceito 26 de abril de 2021 Publicado online 30 de maio de 2021

Cite este artigo: Souza et al. (2021) Inibidores da enzima conversora de angiotensina são fatores de risco ou proteção na COVID-19? Multidisciplinary Reviews4: e2021017. DOI: $10.29327 /$ multi.2021017

\section{Angiotensin converting enzyme inhibitors are risk or protection factors in COVID-19?}

ABSTRACT After the identification of angiotensin-converting enzyme II (ACE2) as a functional receptor for SARS-CoV-2, it was hypothesized that the chronic use of ACE2 inhibitors and angiotensin AT1 receptor blockers (ARBs II) might be related to the positive regulation of the enzyme in several tissues, and therefore to an increased susceptibility to the virus. The hypothesis provoked divergent opinions since contrary evidence showed that a low expression of ACE2 is involved in the pathological process of lung injury after viral infection. We aimed to review the literature on the risk or benefit of chronic use of antihypertensive drugs in patients exposed to the SARS-CoV-2 virus. The MEDLINE/PubMed ${ }^{\circ}$ database was searched using the following keywords: "Angiotensin-converting enzyme inhibitors"; "Angiotensin II receptor blockers"; "Hypertension"; "SARS-CoV-2"; "COVID-19". The search resulted in 230 publications. After reading the available abstracts and full articles, 14 studies were selected that showed content compatibility with the theme. Although there is a lack of consensus among researchers, the use of these drugs should not be interrupted until further evidence is obtained about the use of antihypertensive drugs in patients exposed to the SARS-CoV-2 virus.

KEYWORDS: angiotensin-converting enzyme inhibitors; angiotensin II receptor blockers; hypertension; SARS-CoV-2 


\section{Introdução}

A enzima conversora de angiotensina II (angiotensin-converting enzyme 2), ou ECA2, é uma proteína transmembranar expressa na superfície celular de pneumócitos tipo 2 , bem como em células de outros tecidos. Li et al (2017), aventaram a existência de uma relação contra-reguladora entre a ECA2 e seu homólogo, a enzima conversora de angiotensina (ECA).

Em 2020, Hoffmann et al forneceram evidências inequívocas de que a enzima atua como receptor da proteína Spike, por meio da qual o vírus SARS-CoV-2, entra na célula hospedeira. A ligação da proteína Spike à ECA2, juntamente com a clivagem proteolítica da ECA2 pela enzima protease transmembranar 2 (codificada pelo gene TMPRSS2), medeia a entrada do vírus nas células, a replicação viral e a transmissão célula a célula.

A enzima ECA2, encontra-se ligada às membranas celulares e presente na circulação apenas na sua isoforma solúvel, sendo fortemente expressa no epitélio de diferentes órgãos, como o intestino delgado, testículo, rins, coração, tireoide e tecido adiposo, enquanto o sangue, baço, medula óssea, cérebro, vasos sanguíneos e músculos apresentam níveis baixos de expressão. Nos pulmões, cólon, fígado, bexiga, e glândula supra-renal, foram observados níveis moderados de sua expressão (Li et al 2020).

A ECA2 e sua homóloga, a enzima conversora de angiotensina (ECA) apresentam diferentes funções-chave no sistema renina-angiotensina (SRA). Enquanto a ECA cliva a angiotensina I gerando angiotensina II (Ang II) de ação vasoconstritora, a ECA2 inativa Ang II, degradando-a em angiotensina 1-7 cuja ação protetora, atua como um regulador negativo do sistema. Nos pulmões, sua desregulação favorece a progressão de processos inflamatórios e trombóticos desencadeados pela hiperatividade local de Ang II (Guo et al 2020).

Embora ECA2, confira efeitos protetores em circunstâncias fisiológicas, incluindo a manutenção da homeostase cardiovascular, equilíbrio de líquidos e eletrólitos, sua expressão aumentada, particularmente, no trato respiratório, poderia, em hipótese, estar relacionada a maior infectividade pelo vírus SARS-CoV-2, e desse modo, o uso crônico de inibidores da enzima conversora de angiotensina (iECAs) e bloqueadores de receptores de angiotensina (BRAs), exporia pacientes hipertensos a um risco aumentado de infecção por SARS-CoV-2, haja vista que embora a enzima não seja diretamente antagonizada pelos fármacos anti-hipertensivos, sua expressão se mostra aumentada em vários tecidos, devido ao tratamento crônico com essa classe medicamentosa (Guo et al 2020).

Assim, a questão suscitada sobre o uso crônico de fármacos anti-hipertensivos em pacientes expostos ao vírus SARS-CoV-2, motivou a presente investigação. Objetivamos com esse estudo revisar a literatura acerca do risco ou benefício do uso crônico de fármacos anti-hipertensivos em pacientes expostos ao vírus SARS-CoV-2.

\section{Métodos}

Trata-se de uma revisão narrativa da literatura, realizada na base de dados indexados do MEDLINE/PubMed ${ }^{\circ}$, utilizando os descritores na língua inglesa: Angiotensin-converting enzyme inhibitors, Angiotensin II receptor blockers, Hypertension, SARS-COV-2, COVID-19.

A busca resultou em 230 publicações. Após a leitura de resumos e artigos completos disponíveis, foram selecionados 14 estudos que apresentaram compatibilidade com o tema.

\section{Resultados e Discussão}

Contrapondo a tese de que o uso crônico de inibidores da enzima conversora de angiotensina (iECAs) e bloqueadores de receptores de angiotensina (BRAs), exporia pacientes hipertensos a um risco aumentado de infecção por SARS-CoV-2, Wang et al (2021), demonstraram que a expressão de ECA2 é extremamente baixa em vários tecidos humanos, especialmente no trato respiratório. Os autores calcularam a porcentagem da expressão da enzima no jejuno (células 426/3075), duodeno (células 95/2305), rins (células 681/20.053), pulmões (células 16/17.628) e traqueia (células 20/9521). Em síntese, a ECA2 foi expressa em menos de $1 \%$ das células de tecidos como o coração (0,3\%), fígado 
$(0,1 \%)$, cérebro (0\%), pulmões $(0,1 \%)$ e traqueia $(0,2 \%)$. Os achados contrapõem-se ao estudo anterior de Li et al (2020), os quais encontraram níveis moderados de ECA2 no trato respiratório.

Além da baixa expressão de ECA2 referida por Wang et al (2021), a concentração plasmática de Ang II se mostrou significativamente elevada em pacientes da COVID-19, exibindo correlação linear positiva com a carga viral e lesão pulmonar. A ativação do SRA pode causar disfunção endotelial generalizada e graus variados de lesões em múltiplos órgãos. Assim, o uso de iECAs/BRAs provavelmente ameniza a lesão pulmonar e reduz danos cardíacos e renais resultantes da ativação do eixo endócrino (South et al 2020).

Considerando os supostos mecanismos, ainda indefinidos, de uma ação protetora ou deletéria, aventou-se que pacientes em uso crônico de iECAs e BRAs não deveriam interromper sua administração, até que maiores evidências fossem obtidas acerca do uso dos fármacos anti-hipertensivos em pacientes expostos ao vírus SARS-CoV-2 (Wang et al 2021).

Fang et al (2020) aduziram que o tratamento do diabetes e da hipertensão com medicamentos estimulantes da ECA2 aumenta o risco do desenvolvimento da forma grave e letal da COVID-19. A suposição foi embasada pelo fato dos coronavírus patogênicos humanos SARS-CoV e SARS-CoV-2 se ligarem às células-alvo por meio da enzima ECA2 expressa em células epiteliais do pulmão, intestino, rim, e vasos sanguíneos. O estudo verificou que a expressão da ECA2 é substancialmente aumentada em pacientes com diabetes mellitus tipo 1 ou tipo 2, tratados com inibidores da ECA e bloqueadores dos receptores da angiotensina II tipo I. No caso da hipertensão arterial, os fármacos também são amplamente usados, o que resulta em regulação positiva da ECA2. Os dados sustentaram a hipótese de que a expressão aumentada de ECA2 nos pacientes que fazem uso crônico de iECAs e BRAs aumenta a gravidade da infecção por SARSCoV-2 (Fang et al 2020).

A partir da reanálise de dados transcriptômicos de 700 amostras de pulmão disponíveis em um repositório público de dados genômicos funcionais, GEO (Gene Expression Omnibus), foi comparado o perfil da expressão gênica de portadores de doenças crônicas ao de indivíduos saudáveis. Os resultados revelaram uma alta expressão da ECA2 nos portadores de doenças crônicas, se comparados, aos controles. Os achados sugeriram que doenças pulmonares crônicas podem, em hipótese, alterar a programação epigenética do organismo, tornando algumas enzimas mais ativas e, consequentemente, explicar a regulação positiva da ECA2, favorecendo a infecção viral (Pinto et al 2020).

No entanto, a base genética da expressão e função da ECA2 em diferentes populações ainda é desconhecida. Relatórios recentes da análise da expressão da ECA2 em tecidos pulmonares de populações asiáticas e caucasianas mostram-se controversos (Cao et al 2020).

Uma análise de sequenciamento de RNA de célula única (RNA-seq) indicou que os homens asiáticos podem ter maior expressão de ECA2. Porém os pesquisadores aduziram que as células que expressam a enzima, representam uma parte reduzida das células presentes nos tecidos pulmonares (Zhao et al 2020). Depreende-se, que o nível de expressão e o padrão de expressão da ECA2 humana em diferentes tecidos podem ser críticos para a suscetibilidade, sintomas e resultado da infecção viral (Li et al 2005).

Guo et al (2020), sugeriram que em pacientes infectados, embora uma expressão mais elevada de ECA2 possa estar associada a cargas virais mais altas, os iECAs/BRAs não deveriam ser descontinuados, pois protegem os pacientes contra possíveis lesões cardíacas e reduzem a gravidade da doença pulmonar. No entanto, os pesquisadores não veem necessidade de iniciar imediatamente o uso dos fármacos, por não existirem evidências definitivas de que eles beneficiem a sobrevida dos pacientes infectados por SARS-CoV-2.

Yang et al (2020), observaram que a administração de iECAs/BRAs em pacientes hipertensos com COVID-19 reduziu o risco de mortalidade $(O . R=0,4)$.

Um estudo de coorte retrospectivo, com pacientes hipertensos diagnosticados para COVID-19 e internados em 17 hospitais de referência no Irã, concluiu que iECAs/BRAs são fatores de proteção contra mortalidade nesses pacientes. $O$ estudo mostrou que o uso de destes fármacos foi um fator de proteção contra a mortalidade no modelo, quando ajustado para condições subjacentes, como tempo de permanência, idade, gênero e admissão na UTI $(P<0,001,0 . R=$ $0,5 ;$ I.C $95 \% 0,3 ; 0,7)$ (Yahyavi et al 2020).

Wang et al (2021), constataram que o receptor da proteína tirosina quinase, codificado pelo gene $A X L$ interage especificamente com o domínio $\mathrm{N}$-terminal de SARS-CoV-2. O estudo demonstrou a superexpressão de $A X L$ em células 
HEK293T promovendo a entrada de SARS-CoV-2 tão eficazmente quanto a superexpressão de ECA2. A eliminação de AXL reduziu significativamente a infecção por SARS-CoV-2 em células pulmonares H1299 e em células epiteliais pulmonares primárias humanas. Desse modo, SARS-CoV-2 foi capaz de utilizar tanto a ECA2 quanto AXL para a entrada em células humanas, uma vez que a última é amplamente expressa em quase todos os órgãos humanos, principalmente em células e tecidos epiteliais pulmonares e brônquicos, onde sua expressão é muito maior do que a expressão da ECA2.

\section{Considerações finais}

Embora seja observada a falta de consenso entre pesquisadores, o uso destes fármacos não deve ser interrompido até que maiores evidências sejam obtidas acerca do uso dos fármacos anti-hipertensivos em pacientes expostos ao vírus SARS-CoV-2.

\section{Declaração de conflito de interesse}

Os autores declaram que não há conflitos de interesse.

\section{Financiamento}

Esta pesquisa não recebeu nenhum apoio financeiro.

\section{Referências}

Cao Y, Li L, Feng Z, Wan S, Huang P, Sun X, Wen F, Huang X, Ning G, Wang W (2020) Comparative genetic analysis of the novel coronavirus (2019nCoV/SARS-CoV-2) receptor ACE2 in different populations. Cell Discov 6:11.

Fang L, Karakiulakis G, Roth M (2020) Are patients with hypertension and diabetes mellitus at increased risk for COVID-19 infection? Lancet Respir Med 8:e54

Guo J, Huang Z, Lin Z, Lv J (2020) Coronavirus Disease 2019 (COVID-19) and Cardiovascular Disease: A Viewpoint on the Potential Influence of Angiotensin-Converting Enzyme Inhibitors/Angiotensin Receptor Blockers on Onset and Severity of Severe Acute Respiratory Syndrome Coronavirus 2 Infection. JAHA 9:e016219.

Hoffmann M, Kleine-Weber H, Schroeder S, Kruger N, Herrler T, Erichsen S, Schiergens TS, Herrler G, Wu NH, Nitsche A, Muller MA, Drosten C, Pohlmann S (2020) SARS-CoV-2 Cell Entry Depends on ACE2 and TMPRSS2 and Is Blocked by a Clinically Proven Protease Inhibitor. Cell 181:271-280.

Li MY, Li L, Zhang Y, Wang XS (2020) Expression of the SARS-CoV-2 cell receptor gene ACE2 in a wide variety of human tissues. Infect Dis Poverty 9:45.

Li W, Zhang C, Sui J, Kuhn JH, Moore MJ, Luo S, Wong SK, Huang IC, Xu K, Vasilieva N, Murakami A, He Y, Marasco WA, Guan Y, Choe H, Farzan M (2005) Receptor, and viral determinants of SARS-coronavirus adaptation to human ACE2. EMBO J 24:1634-43.

Li XC, Zhang J, Zhuo JL (2017) The vasoprotective axes of the renin-angiotensin system: physiological relevance and therapeutic implications in cardiovascular, hypertensive and kidney diseases. Pharmacol Res 125:21-38.

Pinto BGG, Oliveira AER, Singh Y, Jimenez L, Goncalves ANA, Ogava RLT, Creighton R, Peron JPS, Nakaya HI (2020) ACE2 Expression is Increased in the Lungs of Patients with Comorbidities Associated with Severe COVID-19. medRxiv 20040261.

South AM, Tomlinson L, Edmonston D, Hiremath S, Sparks MA (2020) Controversies of renin-angiotensin system inhibition during the COVID-19 pandemic. Nat Rev Nephrol 16:305-307.

Wang S, Qiu Z, Hou Y, Deng X, Xu W, Zheng T, Wu P, Xie S, Bian W, Zhang C, Sun Z, Liu K, Shan C, Lin A, Jiang S, Xie Y, Zhou Q, Lu L, Huang J, Li X (2021) AXL is a candidate receptor for SARS-CoV-2 that promotes infection of pulmonary and bronchial epithelial cells. Cell Res 31:126-140.

Yang G, Tan Z, Zhou L, Yang M, Peng L, Liu J, Cai J, Yang R, Han J, Huang Y, He S (2020) Effects of angiotensin II receptor blockers and ACE (angiotensinconverting enzyme) inhibitors on virus infection, inflammatory status, and clinical outcomes in patients with COVID-19 and hypertension: a singlecenter retrospective study. Hypertens 76:51-58.

Yahyavi A, Hemmati N, Derakhshan P, Banivaheb B, Karimi Behnagh A, Tofighi R, TehraniYazdi A, Kabir A (2020) Angiotensin enzyme inhibitors and angiotensin receptor blockers as protective factors in COVID-19 mortality: a retrospective cohort study. Intern Emerg Med 21:1-11.

Zhao Y, Zhao Z, Wang Y, Zhou Y, Ma Y, Zuo W (2020) Single-cell RNA expression profiling of ACE2, the putative receptor of Wuhan 2019-nCoV. Am J Respir Crit Care Med 202:756-759. 